\title{
Neonatal Kasabach-Merritt Syndrome (KMS): case report
}

\author{
Rathia SK ${ }^{1}$, Phuljhele ${ }^{2}$, Gandhi A ${ }^{3}$ \\ ${ }^{1}$ Dr. Santosh Kumar Rathia, Assistant Professor, Department of paediatrics, Pt. JNM Medical College, Raipur; ${ }^{2}$ Dr. \\ Sharja Phuljhele, Professor and Head, Department of Paediatrics, Pt. JNM Medical College, Raipur; ${ }^{3}$ Dr. Animesh \\ Gandhi, Junior Resident, Department of Paediatrics, Pt. JNM Medical College and Dr. Bhim Rao Ambedkar Memorial \\ Hospital, Raipur (C.G), India.
}

Address for Correspondence: Dr. Santosh Kumar Rathia, Email: drsantoshrathia84@gmail.com

\begin{abstract}
A 2days baby girl presented with congenital reddish-blue swelling over chest and abdomen with thrombocytopenia. The clinical, imagining and laboratory findings suggested the diagnosis of KMS. Oral steroid was started with initially needed platelet and FFP transfusions. Large thoracic hemangioma was non-amenable to surgical and radiological interventions. Vincristine was initiated after 2 week trial of Prednisolone for persistent thrombocytopenia and non-regressing haemangioma. Over a week the lesion shrunk with improving platelet count. Vincristine was stopped after 4 weeks in view of no further tumour shrinkage. The patient was discharged on steroid advised for 6-12 months and showed significant tumour regression at 3 month.
\end{abstract}

Key words: Kasabach-Merritt syndrome, haemangioma, thrombocytopenia, corticosteroid, vincristine

\section{Introduction}

Hemangiomas constitute the commonest paediatric neoplasm. The management of these benign lesions not only depends upon their size and site but also on vascular characteristics or certain complications [1]. The triad of hemangioma, thrombocytopenia and consumption coagulopathy is known as KasabachMerritt phenomenon [1]. Hypotheses suggest that exposure of sub endothelial elements or abnormal endothelium within the haemangioma results in aggregation and activation of platelets with a secondary consumption of clotting factors [2].

This case report describes a neonate with KasabachMerritt syndrome (KMS). The clinical presentation of the case and its outcome with possible treatment modalities has been discussed in the light of similar cases/studies reported [3-8]

\section{Case Report}

A female baby born to a non-consanguineous couple presented with a diffuse reddish blue swelling over chest and upper abdomen, present since birth. Although normally delivered at term with no perinatal insults/ trauma, the baby got admitted in private nursery in view of suspected hematoma or ? vascular lump (see figure 1). She was referred from there on $2^{\text {nd }}$ day to our NICU to rule out bleeding diathesis with thrombocytopenia (leading to enlarging hematoma). On examination at admission, baby had mild respiratory distress with RR-68/min, HR- 152/min, CFT<3sec, pulse- normal, Spo2- 99\% with O2 with minimal retractions, but no lethargy. On local examination- reddish blue diffuse swelling with few petechiae was seen over chest and abdomen, with predominant bulge over right upper chest; the swelling was smooth, firm, non tender and warm to touch. Abdominal/other systemic examinations including growth parameters were normal. There were no dysmorphism/organomegaly/neurocutaneous markers.

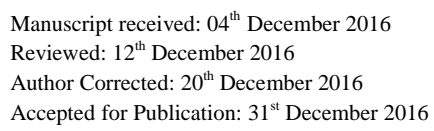




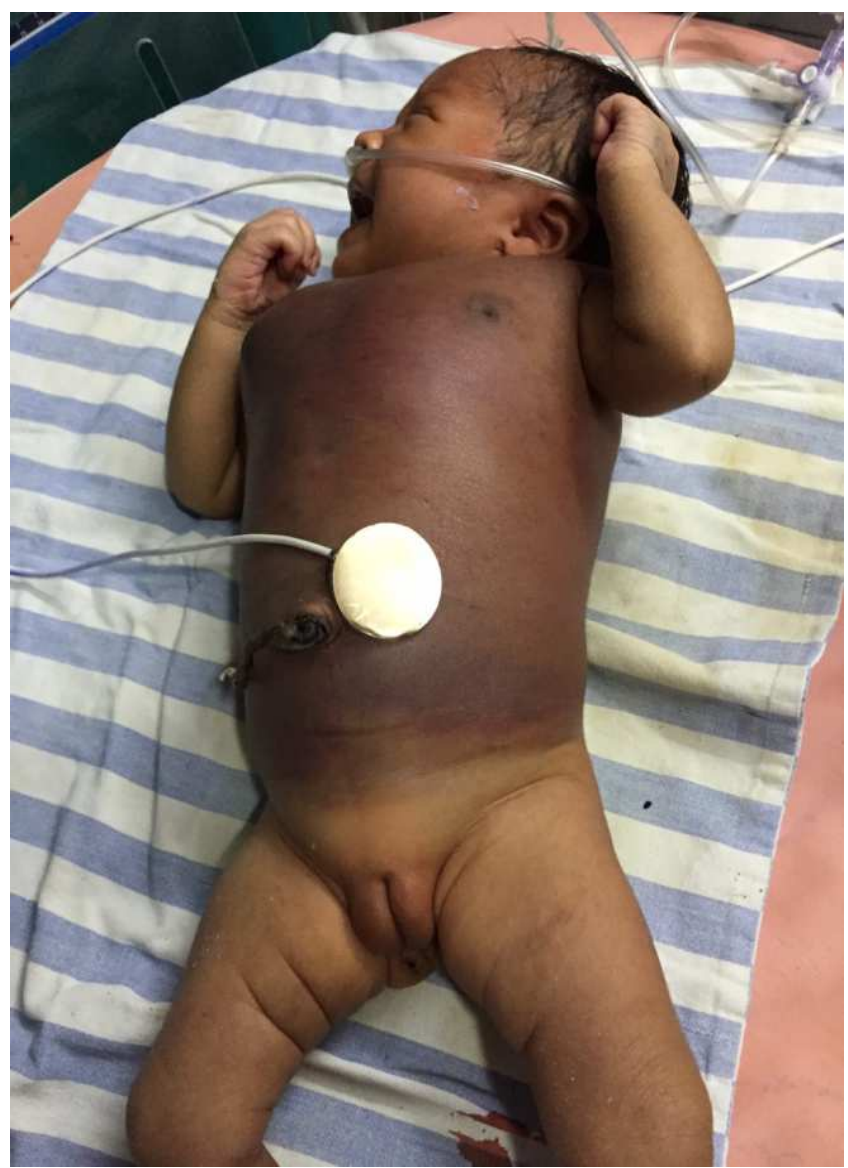

Figure-1: The 2 days old newborn having reddish blue diffuse swelling of chest and abdominal wall (most prominent bulge over right chest wall).

The initial investigations showed normal liver and renal function; but complete blood counts and coagulogram were suggestive of coagulopathy with negative sepsis screen and sterile blood cultures [ normal INR=1.14(on post FFP sample), with FDP>30(raised) and reduced platelet count=94,000/cumm].

With the clinical picture of hemangiomatous lesion over right chest wall and Ultrasound also confirming it as large heterogenous vascular/capillary hemangioma, possibility of hematoma (due to sepsis or DIC) was ruled out. Considering the case as KMS with large thoracic haemangioma, the baby was initiated on supportive treatment with oxygen, IVF, vitamin $\mathrm{K}$ and antibiotics.

Although the patient had received FFP outside and PT/INR was normal at admission, later in NICU course, she required frequent platelet transfusions for recurrent thrombocytopenia along with few plasma. Meanwhile, on day 3 , the baby developed deep jaundice (indirect NNHB, DCT-ve) which resolved after phototherapy. On day4, the child had developed increased purpuric rash on swelling with reduced platelet (5000/cumm), deranged PT/APTT and reduced fibrinogen.

Platelets and FFP were transfused for worsening coagulopathy (DIC). The relevant haematological investigations carried out during 8 weeks of hospital stay have been shown in Table 1(annexure). CT findings of chest swelling were suggestive of a large cavernocapillary haemangioma. The overall clinical course, imaging and laboratory findings confirmed the diagnosis of KMS. USG cranium/abdomen and echocardiography ruled out other systemic vascular malformations.

Once CT angiography also failed to locate definite feeding vessel, the intervention radiologist denied for arterial embolization and in view of diffuse haemangioma with risk of fatal hemorrhage, pediatric surgeons and radiotherapist also denied for surgical or laser therapy. Finally, we decided to watch its course on medical management only. On drug 
therapy, first tried was 2 week trial of oral Prednisolone $(2 \mathrm{mg} / \mathrm{kg} / \mathrm{d})$ and observation was static size of haemangioma with somewhat improved platelet.

But, later in view of non regression of tumour size and recurrent thrombocytopenia, after consulting oncologist for chemotherapy options, intravenous Vincristine $(0.5 \mathrm{mg} / \mathrm{kg} /$ day once weekly) was opted along with oral steroid. One week after the start of Vincristine, the size of the lesion decreased almost to half and platelet count increased to 50,000/cumm, which over 2-3 weeks improved up to 65000/cumm. Vincristine, in the same dose, was continued for total 4 weeks and then stopped as later no further improvement in lesion size or platelet count was noticed.

Table : 1

\begin{tabular}{|c|c|c|c|c|}
\hline $\begin{array}{c}\text { Days of life } \\
\text { (age) }\end{array}$ & Platelet count & Hemoglobin & WBC & Other specific lab investigations \\
\hline $\begin{array}{c}\text { Day2 } \\
\text { (morning } \\
\text { sample; at } \\
\text { admission) }\end{array}$ & 94000 & 13.6 & 14800 & $\begin{array}{l}\text { Initial } \mathrm{PT}=15 \mathrm{sec}, \mathrm{INR}=1.14 \text { (normal value ?post } \\
\begin{aligned} &\mathrm{FFP}), \text { but } \mathrm{FDP}(\text { fibrin degradation } \\
&\text { products })=> 30(\text { raised }), \mathrm{CRP}=12.2 \mathrm{mg} / \mathrm{L}, \\
& \mathrm{uESR}=10 \mathrm{~mm} \text { at } 1 \mathrm{Hr}\end{aligned}\end{array}$ \\
\hline $\begin{array}{c}\text { Day2 } \\
\text { (evening) }\end{array}$ & 47000 & 12.3 & 10600 & $\begin{array}{c}\text { Serum urea=33mg/dl, creatinine }=0.9 \mathrm{mg} / \mathrm{dl} \text {, } \\
\text { SGOT=24 IU/L, SGPT=10 IU/L, ALP=105 IU/L, } \\
\text { total protein=5.1 } / \mathrm{dl} \text {, albumin=3.4g/dl, } \\
\text { serumCa+=10.6mg } / \mathrm{dl}, \text { sodium=130meq } / 1 \text {, potassium } \\
=3.7 \mathrm{meq} / 1\end{array}$ \\
\hline Day3 & 14000 & 8.9 & 16700 & $\begin{array}{c}\text { S.Bil- } \mathrm{T}=21.5 \mathrm{mg} / \mathrm{dl}(\text { Direct }=1.8 \mathrm{mg} / \mathrm{dl}), \\
\text { DCT- Negative, } \\
\text { Reticulocytes }=2 \%\end{array}$ \\
\hline Day4 & 5000 & 10.4 & 12500 & $\begin{array}{c}\text { PT }=25 \sec (\text { control: } 13 \mathrm{sec}) \\
\text { APTT=60sec(control: } 25-30 \mathrm{sec}) \\
\text { Fibrinogen }=19.7 \mathrm{mg} / \mathrm{dl}(\mathrm{low})\end{array}$ \\
\hline Day7 & 35,000 & 12.5 & 8400 & BLOOD C/S - sterile \\
\hline Day15 & 5500 & 8.3 & 7400 & - \\
\hline Day21 & 50000 & 10.8 & 8000 & \\
\hline Day28 & 54000 & 8.2 & 9300 & - \\
\hline Day45 & 65000 & 9.9 & 19700 & - \\
\hline $\begin{array}{l}\text { 2months (at } \\
\text { Discharge) }\end{array}$ & 115000 & 12.3 & 10000 & - \\
\hline
\end{tabular}



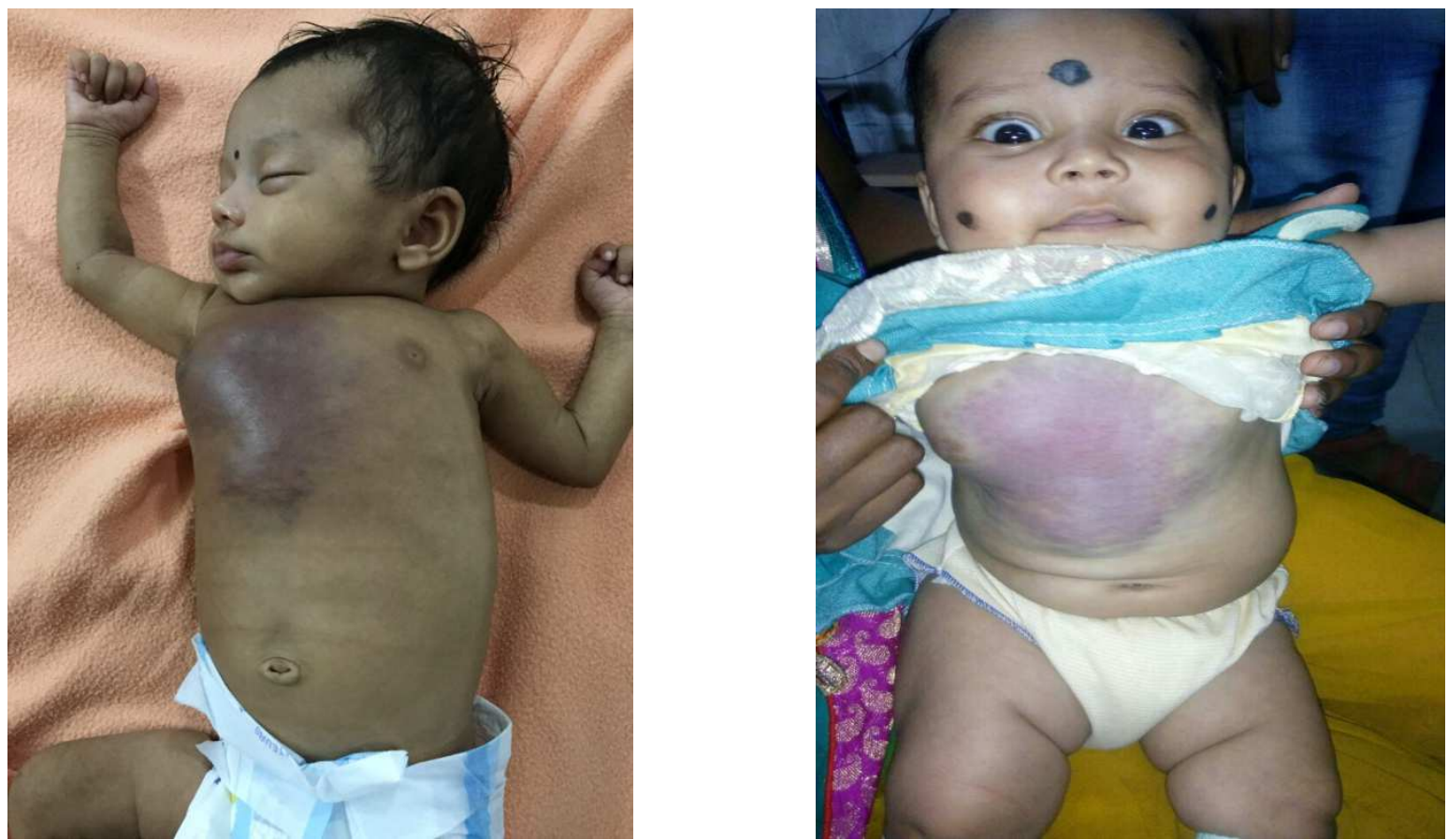

Figure 2: same baby at discharge (2months) and at 4months follow-up

Over 2 months of NICU stay, the baby had considerable regression of haemangioma confined to right upper chest wall (figure 2) and better platelet count persistently recorded $>50000$ /cumm for last 2-3 weeks before discharge. We planned to continue oral Prednisolone for 6-12 months and on follow up more significant tumour regression was observed by 4 months.

\section{Discussion}

Kasabach-Merritt syndrome shows wide variation in its response to different treatment modalities including compression, steroids, chemotherapy, interferon, embolization, sclerotherapy, laser, radiation or surgery [1-6, 9-12]. Currently there is no specific guidelines [13], but various multimodal (stepwise) approaches have been suggested till date $[4,7,8]$. Several researchers agree that most patients with KMS start responding to steroids within few days of treatment [4]. The angiogenetic character of the syndrome indicates that chemotherapy is a logical treatment. Enjolras and associates have reported that several steroid non responders show dramatic response to vincristine [5].

A multicenter study conducted in US showed that vincristine is a safe and effective treatment in the management of KMS [6].. Haisley-Royster reported that the increase in platelet count precedes the regression in tumor size [6].

Usually the mainstay of the treatment is clinical stabilization, tumour regression by medical therapy and/or radio-surgical ablation of hemangioma, the primary culprit. Surgical excision is recommended for single cutaneous lesions or multiple lesions in the spleen (splenectomy) or liver (wedge resection/hepatectomy) $[2,11,12]$.

Any large congenital vascular tumour in newborn with thrombocytopenia with/without significant bleeds must be differentiated from hematoma secondary to sepsis/DIC or liver dysfunction, as hemangiomathrombocytopenia (KMS) syndrome is not very rare; which warrants early appropriate multidisciplinary management. In the index case, unusually diffuse chestwall lesion with complex vascularity made it non amenable to invasive radio-surgical interventions; so steroid and vincristine only could be started. Even then considerable response on both platelet count and tumour regression was observed by 4 months follow up.

\section{Conclusion}

Initial four weeks vincristine with prolonged oral steroid may be the suitable option in KMS for expectant therapy in selected cases with non-feasibility of surgical/radiological interventions. 
Acknowledgements- We acknowledge our colleagues from departments of intervention radiology, radiotherapy, oncology and pediatric surgery for their expert opinion on deciding best possible management of the case.

Funding: Nil, Conflict of interest: None initiated, Permission from IRB: Yes

\section{References}

1. Abass K, Saad H, Kherala M, Abd-Elsayed AA. Successful treatment of kasabach-merritt syndrome with vincristine and surgery: a case report and review of literature. Cases J. 2008 May 23;1(1):9. doi: $10.1186 / 1757-1626-1-9$.

2. Hall GW. Kasabach-Merritt syndrome: pathogenesis and management. Br J Haematol. 2001 Mar;112(4):85162.

3. Blei F, Karp N, Rofsky N, Rosen R, Greco MA. Successful multimodal therapy for kaposiform hemangioendothelioma complicated by KasabachMerritt phenomenon: case report and review of the literature. Pediatr Hematol Oncol. 1998 Aug;15(4):295305 .

4. Hesselmann S, Micke O, Marquardt $\mathrm{T}$, Baas S, Bramswig JH, Harms E, et al. Case report: KasabachMerritt syndrome: a review of the therapeutic options and a case report of successful treatment with radiotherapy and interferon alpha. Br J Radiol. 2002 Feb;75(890):180-4.

5. Enjolras O, Mulliken JB, Wassef M, Frieden IJ, Rieu PN, Burrows PE, et al. Residual lesions after KasabachMerritt phenomenon in 41 patients. J Am Acad Dermatol. 2000 Feb;42(2 Pt 1):225-35.
6. Haisley-Royster C, Enjolras O, Frieden IJ, Garzon M, Lee M, Oranje A, et al. Kasabach-merritt phenomenon: a retrospective study of treatment with vincristine. J Pediatr Hematol Oncol. 2002 Aug-Sep;24(6):459-62.

7. Shin HY, Ryu KH, Ahn HS. Stepwise multimodal approach in the treatment of Kasabach-Merritt syndrome. Pediatr Int. 2000 Dec;42(6):620-4.

8. Wananukul S, Nuchprayoon I, Seksarn P. Treatment of Kasabach-Merritt syndrome: a stepwise regimen of prednisolone, dipyridamole, and interferon. Int $\mathbf{J}$ Dermatol. 2003 Sep;42(9):741-8.

9. Mitsuhashi N, Furuta M, Sakurai H, Takahashi T, Kato S, Nozaki M, et al. Outcome of radiation therapy for patients with Kasabach-Merritt syndrome. Int $\mathbf{J}$ Radiat Oncol Biol Phys. 1997 Sep 1;39(2):467-73.

10. Akyüz C, Emir S, Büyükpamukçu M, Büyükpamukçu N, Cağlar M, Kale G, et al. Successful treatment with interferon alfa in infiltrating angiolipoma: a case presenting with Kasabach-Merritt syndrome. Arch Dis Child. 2003 Jan;88(1):67-8.

11. Drolet BA, Scott LA, Esterly NB, Gosain AK. Early surgical intervention in a patient with Kasabach-Merritt phenomenon. J Pediatr. 2001 May;138(5):756-8.

12. Pasqual E, Bacchetti S, Gasparini D, Sponza M, Cagol PP. Embolisation of arteriovenous intrahepatic fistulas associated with diffuse haemangiomatosis of the liver. Report of a case in an adult and review of the literature. Chir Ital. 2007 Oct;59(5):701-5.

13. Maguiness S, Guenther L. Kasabach-merritt syndrome. J Cutan Med Surg. 2002 Jul-Aug;6(4):335-9. Epub 2002 Apr 15.

\section{How to cite this article?}

Rathia SK, Phuljhele S, Gandhi A. Neonatal Kasabach-Merritt Syndrome (KMS): case report . Int J Med Res Rev 2016;4(12):2176-2180.doi:10.17511 /ijmrr. 2016.i12.16. 